\title{
An Empirical Analysis of Economic Development in Northwest China: Based on the Vicious Circle of Poverty Demands Theory
}

\author{
Peilin $\mathrm{Li}^{1}$ \& Haiying $\mathrm{Ma}^{1}$ \\ ${ }^{1}$ School of Economics, Northwest University for Nationalities, Lanzhou, China \\ Correspondence: Haiying Ma, School of Economics, Northwest University for Nationalities, Lanzhou 730124, China. \\ E-mail: lxmahaiying8888@163.com
}

Received: June 23, 2015

Accepted: July 7, 2015

Online Published: July 15, 2015

doi:10.5430/ijba.v6n4p57

URL: http://dx.doi.org/10.5430/ijba.v6n4p57

\begin{abstract}
China has accelerated economic development and transferred the industrial approach in three decades high-speed growth. However, the economic development level in Northwest still belongs to national low level. This paper took advantage of Nurkse's theory of vicious poverty circle in the demand level. It was analyzed empirically according to the economic index about the consumption, income, investment and region GDP in Northwest. The reason why this region appears situation that its economy is a vicious cycle was discussed. And it would put forward to some suggestions about how to break this vicious poverty cycle.
\end{abstract}

Keywords: consumption, disposable income, fixed assets, regional GDP

\section{Introduction}

In recent years, with the supporting by the new development of the western region, the economic development in Northwest gradually accelerated. In 2013 first quarter, the regional GDP growth speed is about 10\% except NingXia, which exceeds the national average level, at around 3\%. These regions are influenced by the macroeconomic growth downward as well. In addition, the consumption level in Northwest is low. The per capital income is not improved. The investment growth continued fell. It makes that the economic run of Northwest is restricted and the situation of vicious circle is coming.

Breaking the vicious circle of poverty in Northwest, it can improve that the people's living standards and income distribution, especially for the increase of labor reward. Also, it is more significant that making overall plans for Northwest and narrowing the gap between East and West.

In development economics, a vicious circle theory consists of two aspects of the cycle of poverty, one for supply levels to form the "low income-low savings-low capital formation-low productivity-low output-low income"vicious circle. The other demand also created the"low income-low purchasing power-low attractiveness of investment-low output-low income" vicious circle.

Ragnar Nurkse (1953), the development economist, made a systematic presentation about the vicious poverty cycle theory, which explained why economic development in a long-term backwardness.

Domestic research on poverty vicious cycle theory gradually becomes a hit argument after the reform and opening up. Chen Jianxun (1988), his paper analysis the vicious cycle about the poor quality of labor and the backward economical system in the initial reform and opening up. Also, it is important that put forward some policies that we should improve the quality of labor and reform the economic institution, which is consistent with the prevailing economic situation. His paper used the institutional policies to break the vicious cycle. With the financial economic advancing, Yang Xuefeng and Dong Jisheng (2003) discussed that the investment has an affect on the economic development in the poor areas, which is qualitative analysis by the vicious cycle in the supply side. Therefore, they drew a conclusion that encouraging a lot of capital entering the underdeveloped areas and increasing the supply of base currency are useful to change the circle economic model. The vicious circle of poverty is not limited to a single aspect because the reform deepening. Wang Zengsheng (2013) argured that the vicious cycle of poverty, welfare dependency and re-employment income, which is based in econometric model of the six Chinese provinces and discussed the social assistance family income differences between employment and reemployment. They found solutions that measures was taken to support social assistance system. while the income is in the intersection of two 
cycles, it fundamentally solved the vicious poverty problem.

Based on quantitative analysis and qualitative analysis, in this paper the Northwest's consumption, income, investment and regional production ware analyzed empirically, and the corresponding analysis results was obtained, we can put forward some relevant policies about how to break the Northwest's vicious cycle of poverty. Firstly, comparing the average of the five northwest provinces with the national average. Secondly, analyzing the reason why the Northwest region will suffer from the vicious cycle of poverty, which mainly use economic analysis software SPSS and Eviews to establish the relevant econometric model and obtain the intuitive relationship between these variables, so that the economic measures is taken to solve this problem.

\section{The Analysis of Consumption and Income in the Northwest}

\subsection{Comparing to Percentage of National Consumption, Levels of Consumption in Northwest China Are Not Optimistic}

Northwestern provinces are composed of five provinces, which are Shanxi, Gansu, Qinghai, Ningxia Hui Autonomous Region and the Xinjiang Uygur Autonomous Region. Shanxi Province is the best in the level of economic development. By calculating the urban resident per capital consumption expenditure, Shanxi province shows a growth trend on the whole from 2004 to 2013 , which its growth rate was $6.3 \%, 11.9 \%, 10.4 \%, 13.8 \%, 8.7 \%$, $9.4 \%, 14.2 \%, 10.1 \%$ and $8.1 \%$. Comparing the growth rate of the national per capital consumption from 2009 to 2013, Shanxi province is higher than the national level, in around 2\%. However, the Northwest has the poverty backward areas, including the Gansu province, Qinghai province and the Ningxia Hui Autonomous Region, which makes the whole Northwest economic speed slow and below the Shanxi economic level. It means that the development of five provinces in the Northwest is not alike.

Table 1. Comparison of per capital consumption expenditure of urban households from 2004 to 2013

\begin{tabular}{cccccc}
\hline Indicators & 2013 & 2012 & 2011 & 2010 & 2009 \\
\hline Northwest (yuan) & 14953.44 & 13697.02 & 12132.46 & 10572.52 & 9598.12 \\
\hline Indicators & 2013 & 2012 & 2011 & 2010 & 2009 \\
\hline China(yuan) & 18022.6 & 16674.3 & 15160.9 & 13471.5 & 12264.6 \\
\hline $\begin{array}{c}\text { Northwest accounted } \\
\text { for the proportion }\end{array}$ & 0.82 & 0.82 & 0.80 & 0.78 & 0.78 \\
\hline Indicators & 2008 & 2007 & 2006 & 2005 & 2004 \\
\hline Northwest share & 8900.2 & 7901.38 & 6998.64 & 6408.56 & 5904.88 \\
\hline Indicators & 2008 & 2007 & 2006 & 2005 & 2004 \\
\hline China (Yuan) & 11242.9 & 9997.5 & 8696.6 & 7942.9 & 7182.1 \\
\hline $\begin{array}{c}\text { Northwest accounted } \\
\text { for the proportion }\end{array}$ & 0.79 & 0.79 & 0.80 & 0.80 & 0.82 \\
\hline
\end{tabular}

Source: National Bureau of Statistics

As Table 1 shows, in terms of the absolute amount of urban residents per capital consumption expenditure of the Northwest, the per capital consumption level of growth has been improving. Due to advance the development of the logistics industry, it is not limited to making the Northwest market trading entity, the Internet trading improve Northwest's per capital consumption levels, and even the whole country. After the economic crisis, the expansion of effective demand of residents is an important means of national macro-control, including support for the Northwest consumers. However, the per capital consumption expenditure of urban residents in northwest increases. Relating to the national level, the share of consumption is still low ratio, the proportion fluctuated back and forth between 0.78 to 0.82 and the magnitude of its fluctuations is small.

2.2 Compared to the Proportion of National Income, per Capital Disposable Income of the Northwest Is at a Low Level

The income growth has increased in a certain degree. $8.8 \%$ is per capital disposable income of urban residents and 
the $9.9 \%$ is the rural residents'. However, the $9.26 \%$ growth rate has been in the past five years. Compared the income growth rate in the urban residents is no higher than GDP. Among them, the five northwestern provinces of urban residents are also at a disadvantage, it can be seen from the following Table 2. With the economic developing, per disposable income has improved, but significantly below the national average. It illustrates that a low level of economic development of the Northwest leads to the low level per capital income.

Table 2. Northwest and the national urban residents per capital disposable income in 2004-2013

\begin{tabular}{cccccc}
\hline Indicators & 2013 & 2012 & 2011 & 2010 & 2009 \\
\hline Northwest (yuan) & 20605.76 & 18641.84 & 16385.94 & 14345.42 & 13007 \\
\hline Indicators & 2013 & 2012 & 2011 & 2010 & 2009 \\
\hline China(yuan) & 26955.1 & 24564.7 & 21809.8 & 19109.4 & 17174.7 \\
\hline $\begin{array}{c}\text { Northwest accounted } \\
\text { for the proportion }\end{array}$ & 0.76 & 0.76 & 0.75 & 0.75 & 0.75 \\
\hline Indicators & 2008 & 2007 & 2006 & 2005 & 2004 \\
\hline Northwest (yuan) & 11966.26 & 10444.88 & 9047.46 & 8100.1 & 7382.04 \\
\hline Indicators & 2008 & 2007 & 2006 & 2005 & 2004 \\
\hline China(yuan) & 15780.8 & 13785.8 & 11759.5 & 10493 & 9421.6 \\
\hline $\begin{array}{c}\text { Northwest accounted } \\
\text { for the proportion }\end{array}$ & 0.76 & 0.76 & 0.77 & 0.77 & 0.78 \\
\hline
\end{tabular}

Source: National Bureau of Statistics

\subsection{Comparing the National Fixed Investment, the Northwest's Investment Is Poor}

In term of demand, the national economic growth is mainly showing the features export-oriented and investment-oriented. Calculated from 2000 to 2012, the national investment to economic growth in the contribution rate has increased by $30 \%$. According to Chinese statistics in 2013. The contribution rate of investment in Northwest is low.

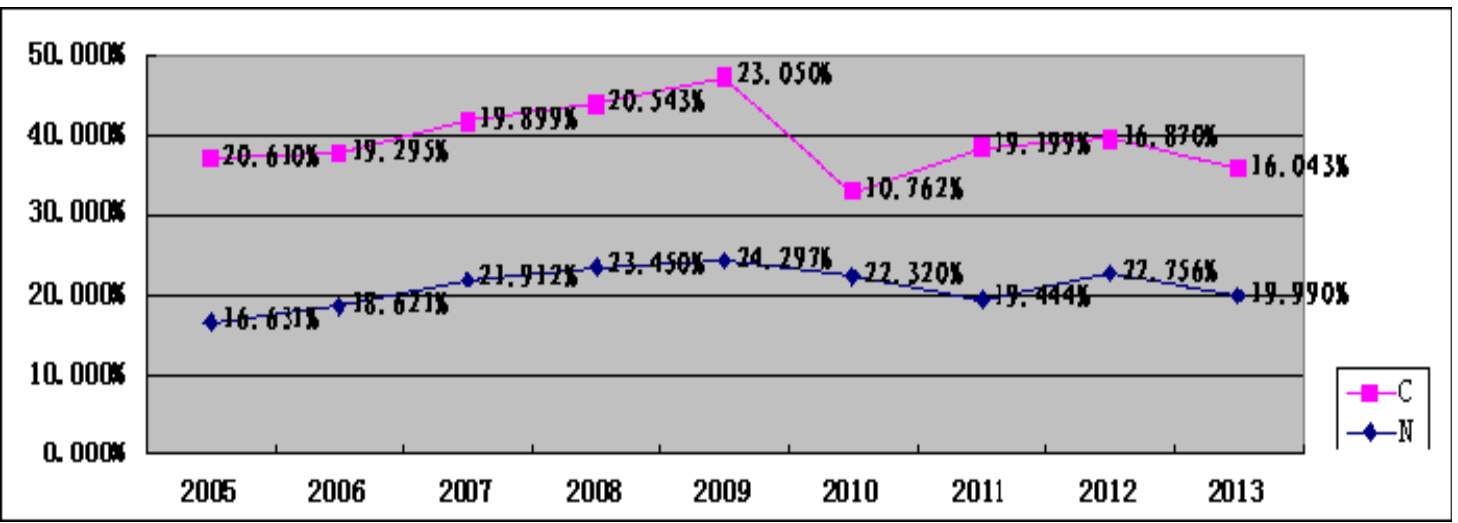

From the above chart shows the percentage growth in fixed asset investment about the Northwest and nation, the C represents the national level of investment and $\mathrm{N}$ represents the level of investment in Northwest. We can conclude that the Northwest fixed investment growth is consistent with the national growth, but below the national average. Comparing with the extent of financing in the eastern coastal town, the Northwest is at a disadvantage.

\subsection{Comparing to National GDP, the GDP in the Northwest Region Is at a Lower Level}

After the reform and opening up, the national economy continues to maintain an average annual growth rate of $9.8 \%$, 
which its GDP ranked to the second place in the world. During this period, the Northwest economy has been a major breakthrough after the development of the western region, the total GDP of the five provinces in the Northwest is in the growing trend. However, by calculating the average proportion Northwestern GDP, we can conclude that the proportion is between $5.052 \%$ to $6.132 \%$.

\section{Causes Analysis of Poverty Vicious Circle in Northwest}

\subsection{Lower Income Leads to the Lower Level of Consumption in Urban Northwest}

Income is the most important variable determining consumption. The higher the income, the higher level of consumption. The effective demand of consumers is the largest as well. When income is used as the only independent variable, that is to say the other factors do not exit, the ordinary least squares regression analysis was performed that the five Northwestern provinces of urban residents per capital consumption and per capital income.X represents the disposable income per urban inhabitant in Northwest, Y represents the expenditure for consumption per urban inhabitant in Northwest.

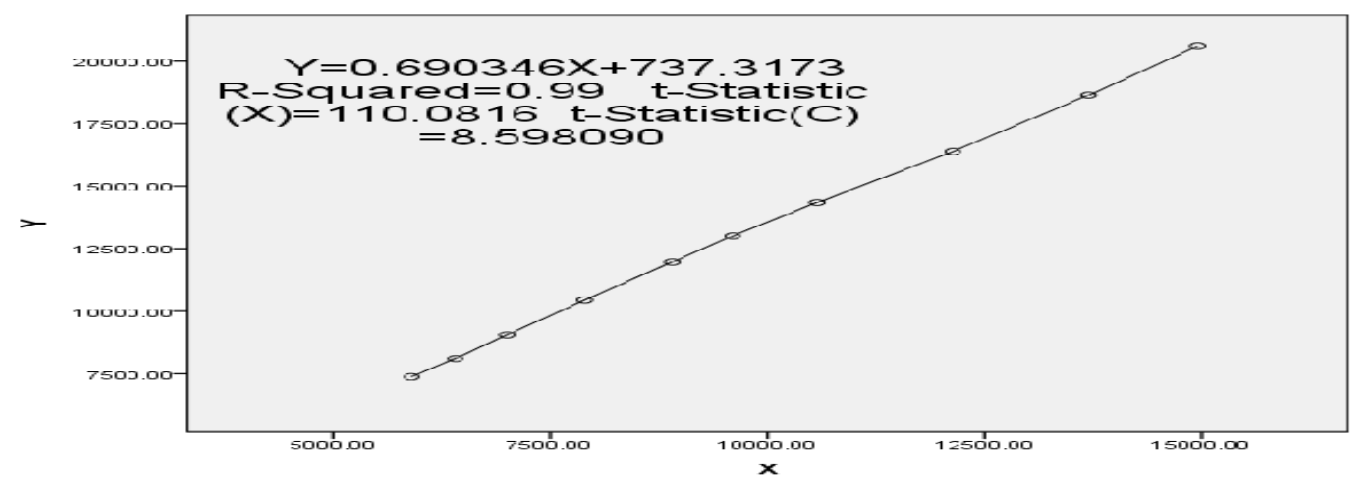

There is the regression equation about the per capital consumption and per capital income.

$$
\mathrm{Y}=737.3173+0.690346 \mathrm{X}
$$

Where $\mathrm{R}$ square is equal to 0.99 , it represents the overall fit better, it passed T-test and shown per capital disposable income and per capital consumption expenditure had a significant relationship. With urban per capital disposable income for every 1 yuan increasing, the expenditure of urban will increase 0.690346 yuan, we can conclude that a large gap exists between the income and consumption in the Northwest, and increasing ratio is inconsistent.

\subsection{Lower Consumption Leads to the Lower Level of Investment in Urban Northwest}

According poverty vicious circle theory, low consumption level will cause lack of investment lure investors, especially the investment in fixed assets in the great gap.

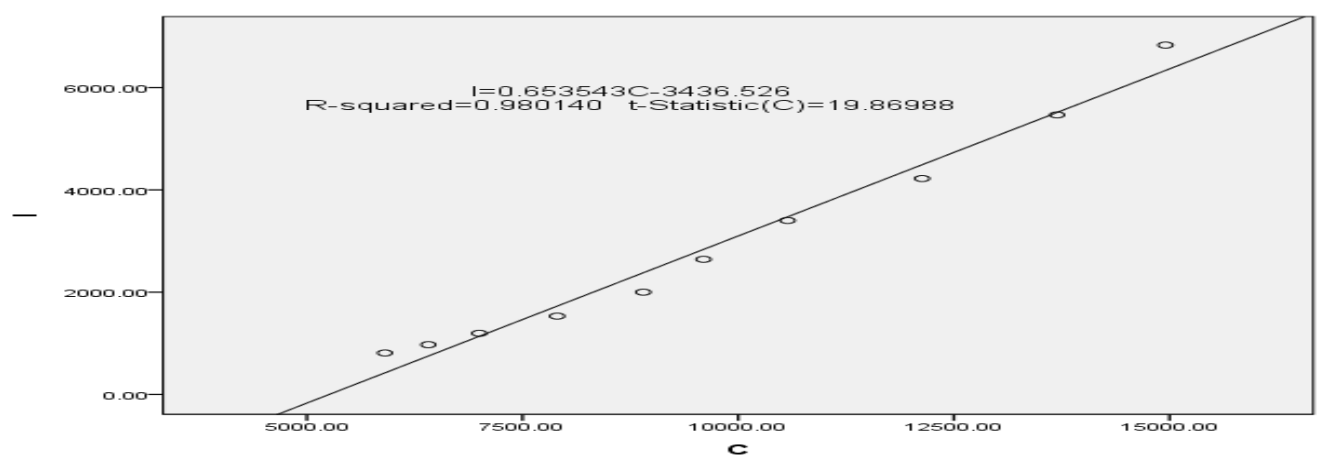

According the above graph, it shows a linear correlation between the overall, Where R square is equal to 0.98 , which 
represents the overall fit better.Because, it means the results passed the T-test. It shows that per capital consumption expenditure has a significant relationship with the northwestern investment in fixed assets.

$$
I=0.653543 \mathrm{C}-3436.526
$$

It indicates that each 1 yuan increasing per capital consumption expenditure of urban fixed asset investment will bring Northwest increasing 65,354,300 yuan.

\subsection{Low Investment Leads to Lower GDP in Northwest of China}

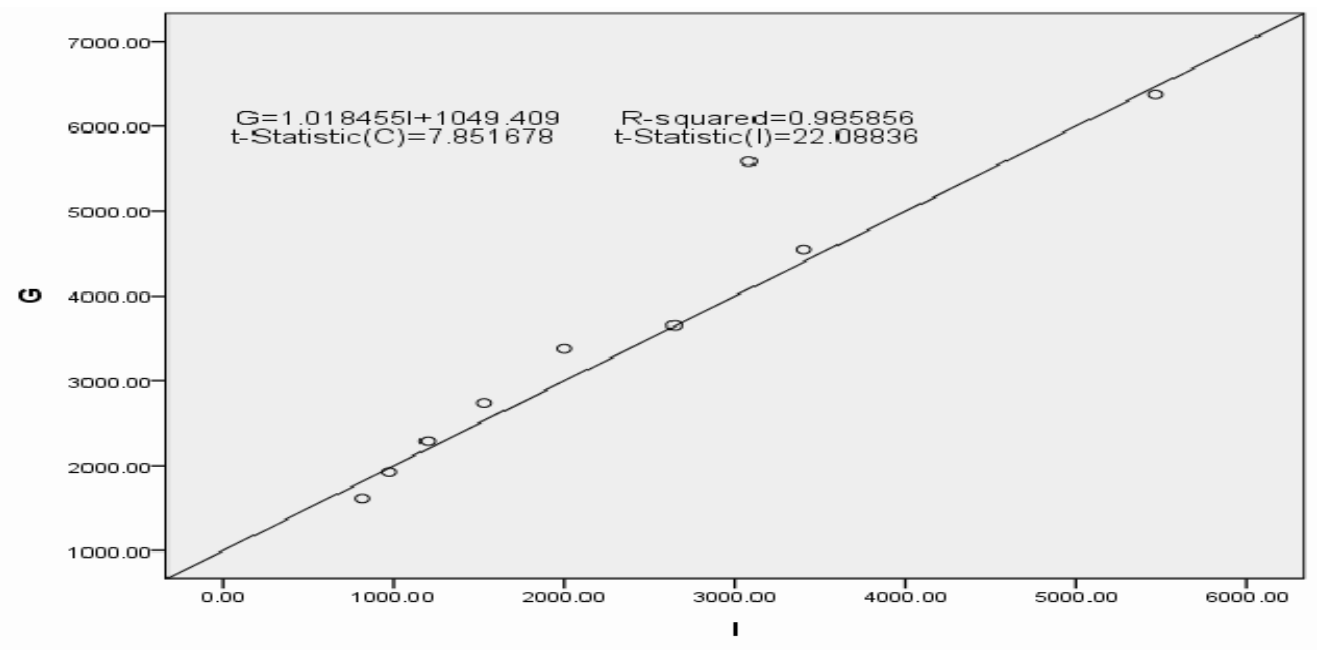

The I represent investment in Northwest, G represents the Northwest GDP. By analyzing relationship of investment and GDP, the figure can be seen in the Northwest, which showed a more significant linear relationship, R square is equal to 0.98. It represents the overall fit better. It passed the T-test and showed that investment in fixed assets has a significant relationship with the gross production of the Northwest. Drawn by the inspection,

$$
G=1.0184551 \mathrm{I}+1049.409
$$

It means that additional 100 million yuan in fixed assets investment will bring the total value of production increased Northwest 1.0184551 billion.

\subsection{Low Levels of GDP in Northwest Lead to Low Income}

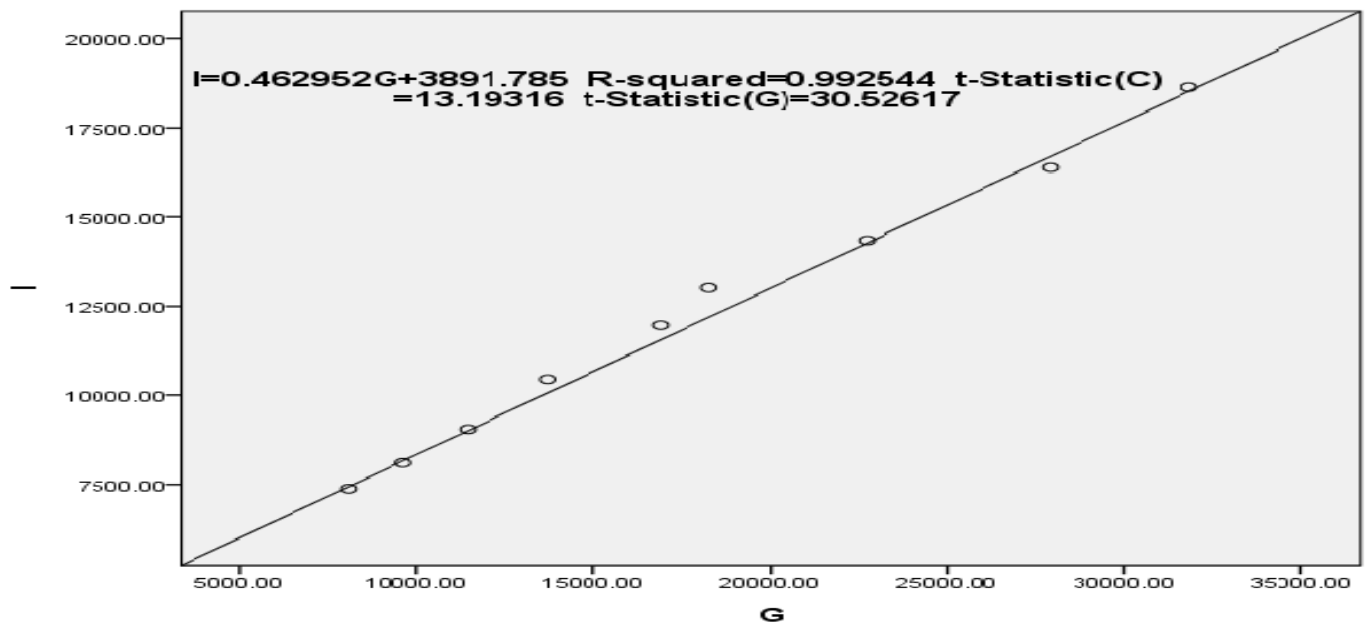


The I represents the per capital disposable income, the G represents the Northwest GDP, the regression results on the map showed a linear relationship. $\mathrm{R}$ square is equal to 0.99 . It means the overall fit better. So we can conclude that 2004-2012 Northwest disposable income and gross production showed a significant relationship in the Northwest.

$$
\mathrm{I}=0.462952 \mathrm{G}+3891.785
$$

It showed each additional 100 million GDP will bring Northwest 0.462952 billion per capital disposable income increasing.

\section{Some Measurements and Policy Considerations}

\subsection{Responded to the Initial Distribution of Income Structure}

Chinese current economic development is consistent with the trend about the urban-rural dual economic model in some way, that is to say, by reducing the wages of labor workers to maintain high capital accumulation, it can ensure rapid economic growth which Including the economic model on mid-90s in the last century, especially the investment-led economic growth model. It makes the labor remuneration in primary distribution declined. Also, the economic development in Northwest fits a pattern of urban and rural.Improving the labor remuneration is a key to break the vicious cycle of poverty.

\subsection{Rational Planning Economic Development}

This plan about how to drive the original industry and stimulate the new industry should be taken into account. The development zone is building step by step, and it should avoid the situation that the investment scale is over widely economy scale in Northwest, which will cause the asset allocated unreasonably. The system must be guaranteed that relevant government transition is not the reason why the process is changed.

\subsection{Encouraging Businesses and Individuals to Invest in the Northwest}

Bank lending rates business investment, encouraging college students venture loan. Reduce government restrictions on business start-ups and new approval procedures and other unreasonable, private investment for economic development of the Northwest region play a crucial role, and gradually the evening service system of private investment financing, the size of its investment in the Northwest Territories for smaller, weaker actual situation, policy and institutional government should encourage and guide private enterprises to finance operations, increase infrastructure to promote the construction of the Northwest, for enterprises to create a good personal investment business environment.

\subsection{Actively Adjusting the Industrial Structure, Especially to Increase Investment in New Industries}

Northwest is the development of a second major industries, its economic development structure is irrational, although in recent years, the tertiary industry grew faster than the second industry, but these are primarily invested in transport traffic communications industry, the existence of a serious shortage of investment in Northwest education and financial services sectors, while the financial services sector is one of the important factors to promote modern service industry, therefore, the Northwest by optimizing the industrial structure of the three overall change from Northwest Industrial Structure, promote industrial restructuring and upgrading, to break the vicious cycle of poor economic model.

\subsection{More Counterpart Aids in the Industrial Transfer Are Needed}

Aiding and helping their counterparts in China to promote economic development and implementation of a particular area of policy assistance, which is also for the economic development and the development of backward regions contributed, Northwest harsh environment, the need counterparts policy assistance to its support, should industrial transfer and aiding the work of combining, which can effectively enhance the effect of their counterparts working to accelerate industrial orderly transition from the east to the northwest. When Northwest undertake industrial transfer, the first to build industrial park road transport. Secondly, to build a more comprehensive enterprise network information system to provide appropriate financial data analysis, to provide comprehensive information support for the transfer.

\section{References}

Cai, D.P. (2006). Statistical analysis of the relationship between regional and national economic development. Chinese Logistics and Purchasing, 6, 74-75 (in Chinese).

Chinese Academy of Economic Reform and Development. (2014, March). China's Economic Reform and Development Report 2014, pp.64-66. 
Gao, S., \& Li, H.C. (2009). Analysis on the function mechanism of industry on national economy in China. Economic Technology, $42-44$ (in Chinese).

Katrin, L. (2008). The State of China's Sector and the Role of Chinese economic development. Chinese Ecomonics, $8(9), 42$.

Li, H.Z., \& Cai, H.G. (2007). Empirical research on the effects of regional industry on China's economic growth. Modern Economics, 59-60 (in Chinese).

Liu, N., \& Li, Y. (2007). Interaction between regional development and economic growth in China. Management Engineering, 7, 151-153 (in Chinese).

National Institute for Economic Reform and Development. (2014, March). China's Economic Reform and Development Report 2014, p.138.

Nyhuis, P., Wriggers, F.S., \& Busse, T.D. (2007). Derivation of Strategic Measures for Forging Systems. IFIP Internation Federation for Information Processing. Advances in Production Management Systems, Boston: Springer, (246), 27-34.

Peng, R.G., Wang, L., \& Yang, Z.H. (2007). Empirical analysis on the regional industry to the role of Yangtze River Delta economic growth. Market Forum, 7, 36-37(in Chinese).

Shao, Y., Yu, Y., Kang, M.J., \& Zhang, Y.S. (2008). Regional industry to promote the effect on the national economy. The national trade and economic core periodicals, 8, 17(in Chinese).

Si, L.S., \& Tong, C. (2007). Analysis on influence of regional development in economic growth. Logistics Technology, 7, 12-14 (in Chinese).

Wang, J. (2007). The analysis of regioanl impact on China's national economy. Science and Technology Advisory Review, 216 (in Chinese).

Wang, J.L. (2008). Research on the correlation between China's regioanl industry and the overall national economy level. Economic Technology, 8, 9-11 (in Chinese).

Wang, J. (2004). Empirical analysis on the effects of China's industry on economic growth. Information Development \& Economy, 4, $69-70$ (in Chinese).

Xu, Y. (2009). Empirical analysis on the effects of China's value-added on GDP growth. Market Modernization, 9 , 152-153 (in Chinese).

$$
a^{2}+b^{2}=c^{2}
$$

Appendix 1. Table title (this is an example of table 1)

\begin{tabular}{lccr}
\hline & Total capital stock & Income of main business & Total assets \\
\hline Pudong Development Bank & 39.2 & 214.7 & 5730.7 \\
Bank of China & 459.4 & 3345.7 & 59876.9 \\
\hline
\end{tabular}

Discription: Place table caption in front of table body and description below the table body. Avoid vertical rules. Be sparing in the use of tables and ensure that the data presented in tables do not duplicate results described elsewhere in the article. 